\title{
Hepatocellular Carcinoma in a Noncirrhotic Liver after Long-Term Use of Danazol for Hereditary Angioedema
}

\author{
Soraya Rahal Marine Gilabert Pauline Ries Sandrine Oziel-Taieb \\ Slimane Dermeche Jean-Luc Raoul \\ Department of Medical Oncology, Paoli-Calmettes Institute, Marseille, France
}

\section{Key Words}

Hepatocellular carcinoma $\cdot$ Danazol $\cdot$ Healthy liver $\cdot$ Drug-induced cancer

\begin{abstract}
We report a 57-year-old male who was treated with high-dose danazol for hereditary angioedema for more than 30 years; he developed hepatocellular carcinoma in the absence of cirrhosis. Despite surgical resection, he had a recurrence and received sorafenib, but had a poor skin tolerance. Such tumors arising after danazol are infrequent, and this case is highly unique due to the minor lesions found on the liver.

(c) 2014 S. Karger AG, Basel
\end{abstract}

\section{Introduction}

Men have a higher incidence of hepatocellular carcinoma (HCC) than women, suggesting a carcinogenic influence of androgens. Some cases of HCC associated with androgen uptake have been reported. Some are due to androgenic-anabolic steroids [1], but most are related to the treatment of diseases, such as Fanconi anemia [2]. Among these androgens, danazol, an inhibitor of gonadotropin with a weak androgenic effect, is frequently used to treat endometriosis, idiopathic thrombocytopenic purpura and hereditary angioedema (HAO) and has hepatic toxicities, including liver tumors, particularly hepatocellular adenoma [3], focal nodular hyperplasia [4] and surprisingly only a few cases of HCC [5]. We report a new case of HCC arising in a noncirrhotic liver in a patient receiving danazol for HAO. 


\section{Case Reports in Oncology}

\begin{tabular}{l|l}
\hline Case Rep Oncol 2014;7:825-827 \\
\hline DOI: $10.1159 / 000370106$ & $\begin{array}{l}\text { C 2014 S. Karger AG, Basel } \\
\text { www.karger.com/cro }\end{array}$ \\
\hline
\end{tabular}

Rahal et al.: Hepatocellular Carcinoma in a Noncirrhotic Liver after Long-Term Use of Danazol for Hereditary Angioedema

\section{Case Presentation}

A 57-year-old male was diagnosed with $\mathrm{HAO}$ at the age of 24, and danazol (400 mg daily) was started some months after the diagnosis and showed a major improvement. In 2010, after 33 years of the same dose without interruption, his serum creatinine level increased, and an US of the kidneys was performed. On this US examination, an 11-cm liver tumor was found. Clinically, the patient was lean $(54 \mathrm{~kg}, 1.68 \mathrm{~m})$. There was a huge, painless, firm liver mass, without any sign of chronic liver disease. There was only a minor increase in alanine aminotransferase (1.6 upper limit of normal); his alpha fetoprotein was normal, and serology for B and C virus infections was negative. On CT scan and contrast-enhanced MRI, the 12-cm tumor was heterogeneous, with a clear washin and an imperfect washout; importantly, the fat content was noted on the MRI. The tumor seemed attached to segment VI, and surgical resection was performed without any difficulty; the liver seemed macroscopically normal. On pathological examination, the tumor was multinodular with necrosis and hemorrhagic areas. Microscopically, the surrounding liver had minor alterations, including minor fibrosis (F1) and some inflammation (A2). The tumor was a moderately differentiated HCC (Edmonson-Steiner grade 3), with a major vascular invasion and necrosis in more than $50 \%$ of the tumor area. The resection was complete, and follow-up was uneventful. Unfortunately, 3 years later, follow-up demonstrated a massive intrahepatic recurrence with more than 10 large nodules, and treatment with sorafenib was initiated at $800 \mathrm{mg} / \mathrm{day}$. A few days later, the patient developed a severe hand-foot syndrome, and after a 2-week break, sorafenib was resumed at a dose of $400 \mathrm{mg} /$ day. The severe hand-foot syndrome recurred within a few days, and after a new break, sorafenib was given at $200 \mathrm{mg} /$ day and was well tolerated. The tumor remained stable for at least 4 months, and the patient tolerated $200 \mathrm{mg} /$ day of sorafenib. Then, sorafenib was stopped after 6 months due to bone progression. Systemic chemotherapy was given, combining gemcitabine and oxaliplatin [6] (noncirrhotic liver), but that could not stabilize the disease. The patient died 13 months after the diagnosis of this recurrence.

\section{Discussion}

HAO is caused by a deficiency of the C1-inhibitor, leading to spontaneous edema. New specific treatments are currently the first choice, but years ago, androgens were frequently used for prophylaxis and are still given to some patients. Our patient developed HCC in a noncirrhotic liver, without any other known cause of HCC, but he had taken a high dose of danazol for decades. In a recent international internet survey (66 physicians), 886 patients [7] received androgens, and only 1 developed HCC. None of the patients who were treated with another drug ( $>1,000$ patients) had HCC. Only a few cases of danazol-induced HCC have been reported in HAO [7], without any data regarding the underlying liver pathology. However, considering the currently available new drugs and the risk of both benign liver tumors (adenoma or focal nodular hyperplasia) and HCC, particularly in patients who have taken danazol for more than 10 years at a dose of more than $100 \mathrm{mg}$ [4], the use of danazol for extended periods of time or at high doses must be avoided. Additionally, these patients must be followed with regular US examinations. The association between sorafenib toxicity and HAO seemed to be incidental in our case. 


\section{Case Reports in Oncology}

\begin{tabular}{l|l}
\hline Case Rep Oncol 2014;7:825-827 \\
\hline DOI: $10.1159 / 000370106$ & $\begin{array}{l}\text { C 2014 S. Karger AG, Basel } \\
\text { www.karger.com/cro }\end{array}$ \\
\hline
\end{tabular}

Rahal et al.: Hepatocellular Carcinoma in a Noncirrhotic Liver after Long-Term Use of Danazol for Hereditary Angioedema

\section{Disclosure Statement}

J.-L.R. received lecture fees from Bayer SP.

\section{References}

1 Farrel GC, Joshua DE, Uren RF, Baird PJ, Perkins KW, Kronenberg H: Androgen-induced hepatoma. Lancet 1975;305:430-432.

-2 Velazquez I, Alter BP: Androgens and liver tumors : Fanconi's anemia and non-Fanconi's conditions. Am J Hematol 2004;77:257-267.

3 Bork K, Pitton M, Harten P, Koch P: Hepatocellular adenomas in patients taking danazol for hereditary angiooedema. Lancet 1999;353:1066-1067.

4 Helsing P, Nielsen EW: Hepatocellular focal nodular hyperplasia after danazol treatment for hereditary angio-oedema. Acta Derm Venereol 2006;86:272-273.

5 Confavreux C, Seve P, Broussolle C, Renaudier P, Ducerf C: Danazol-induced hepatocellular carcinoma. QJM 2003;96:317-318.

6 Zaanan A, Williet N, Hebbar M, Dabakuyo TS, Fartoux L, Mansourbakht T, et al: Gemcitabine plus oxaliplatin in advanced hepatocellular carcinoma: a large multicenter AGEO study. J Hepatol 2013;58:81-88.

7 Kalaria S, Craig T: Assessment of hereditary angioedema treatment risks. Allergy Asthma Proc 2013;34:519-522. 